\title{
CASE REPORT: AXENFELD-RIEGER SYNDROME
}

Tasneem A. F1, Vittal Nayak I², Shwetha B. A ${ }^{3}$, Ali Akbar Jafarian Lari ${ }^{4}$

\section{HOW TO CITE THIS ARTICLE:}

Tasneem A. F, Vittal Nayak I, Shwetha B. A, Ali Akbar Jafarian Lari. "Case Report: Axenfeld-Rieger syndrome:". Journal of Evolution of Medical and Dental Sciences 2014; Vol. 3, Issue 21, May 26; Page: 5945-5949, DOI: $10.14260 /$ jemds/2014/2686

ABSTRACT: Reporting a family in which a father and his 3 sons were diagnosed as Axenfeld- Rieger anomaly. Slit lamp evaluation showed bilateral megalocornea, posterior embryotoxon, corectopia. All had grade 2-3 RAPD, raised intraocular pressure with increased cup/disc ratio and tubular vision. On gonioscopy angles were open with peripheral iris strands. OCT revealed thinned out retinal nerve fiber layer. No other systemic manifestations were noticed.

Thus reporting a family of Axenfeld-Rieger anomaly.

KEYWORDS: Axenfeld-Rieger Anomaly, Megalocornea, Corectopia, Glaucoma, RAPD, Posterior embryotoxon.

INTRODUCTION: Axenfeld- Rieger anomaly is a part of anterior segment dysgenesis which is a failure of normal development of tissues of anterior segment of eye. Axenfeld characterized the anomaly which bears his name when he described posterior embryotoxon and iris strands adherent to the anteriorly displaced Schwalbe's line (1920). ${ }^{1}$

Posterior embryotoxon is a clinical and histological term referring to displacement of Schwalbe's line. ${ }^{2}$ Rieger described the patients with congenital iris abnormalities including iris hypoplasia, corectopia and polycoria as Rieger anomaly which in case associates with systemic findings such as dental, facial bone defects, umbilical, pituitary abnormalities, termed as Rieger Syndrome.

Axenfeld-Rieger Syndrome is a multisystemic genetic disorder inherited in an Autosomal dominant fashion in most of the cases but it can be sporadic also. It has complete penetrance with variable expressivity and associated with $50 \%$ risk of glaucoma.

CASE REPORT: A 25year old male presented with decreased vision in both eyes from 4 years. On examination visual acuity was perception of light present in right eye and absent in left eye. Slit lamp examination revealed megalocornea, measuring vertically $13 \mathrm{~mm}$ and horizontally $14 \mathrm{~mm}$ in both eyes. Posterior embryotoxon was present. Anterior chamber was deep and quiet in both eyes, corectopia was noticed and pupil showed grade 2-3 RAPD on left eye.

On applanation tonometry a raised intraocular pressure of 40 in right eye and $42 \mathrm{~mm}$ of $\mathrm{Hg}$ in left eye was recorded. Fundus findings documented as tessellated background, pale, big disc with peripapillary atrophy, cupping of 0.9 , bayonetting of vessels, thinned neuroretinal rim with loss of retinal nerve fiber layer pattern. Gonioscopy showed Shaffer's grade 4 open angles with peripheral iris strands. OCT revealed average RNFL thickness of 44 and 52 micrometer. It was found that the patient's father and his two brothers were suffering from decreased vision, and they were advised for complete ophthalmic evaluation, which revealed similar findings.

All the 4 patients, father and his 3 sons were found to have axenfeld-rieger anomaly. They all had tubular vision and were given blind certificate. 


\section{CASE REPORT}
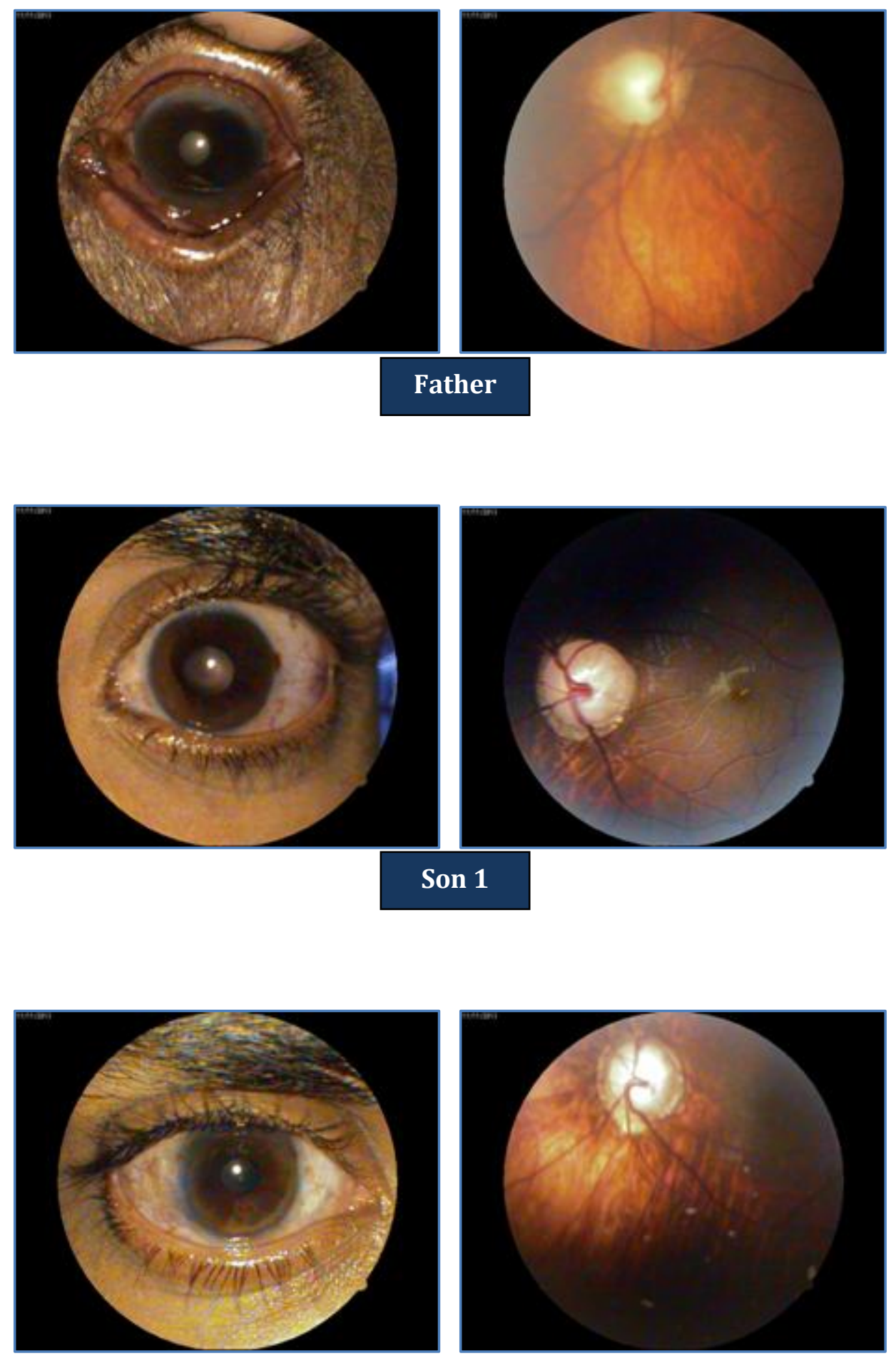

Son 2 


\section{CASE REPORT}
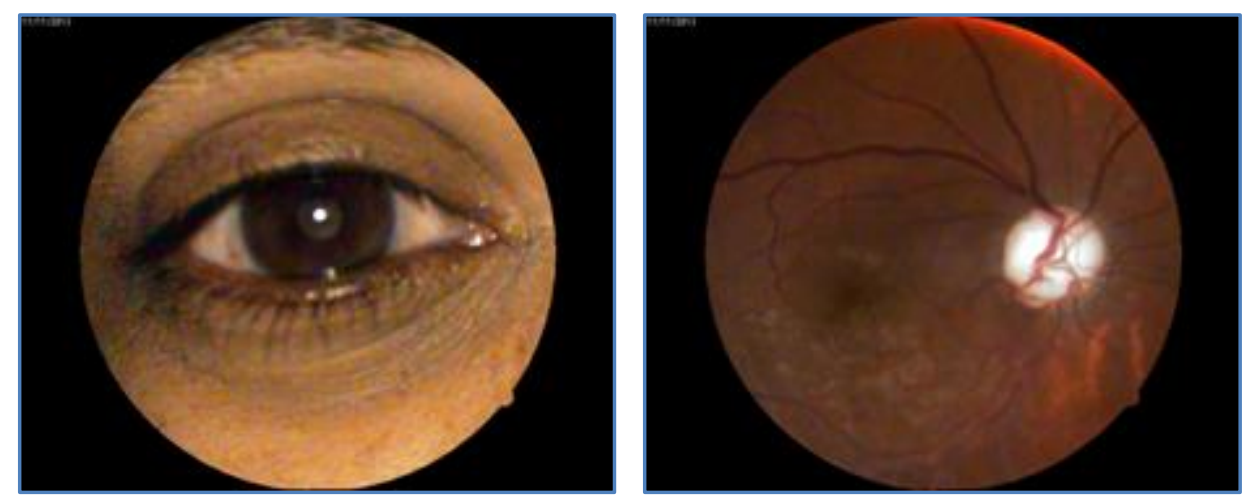

\section{Son 3}

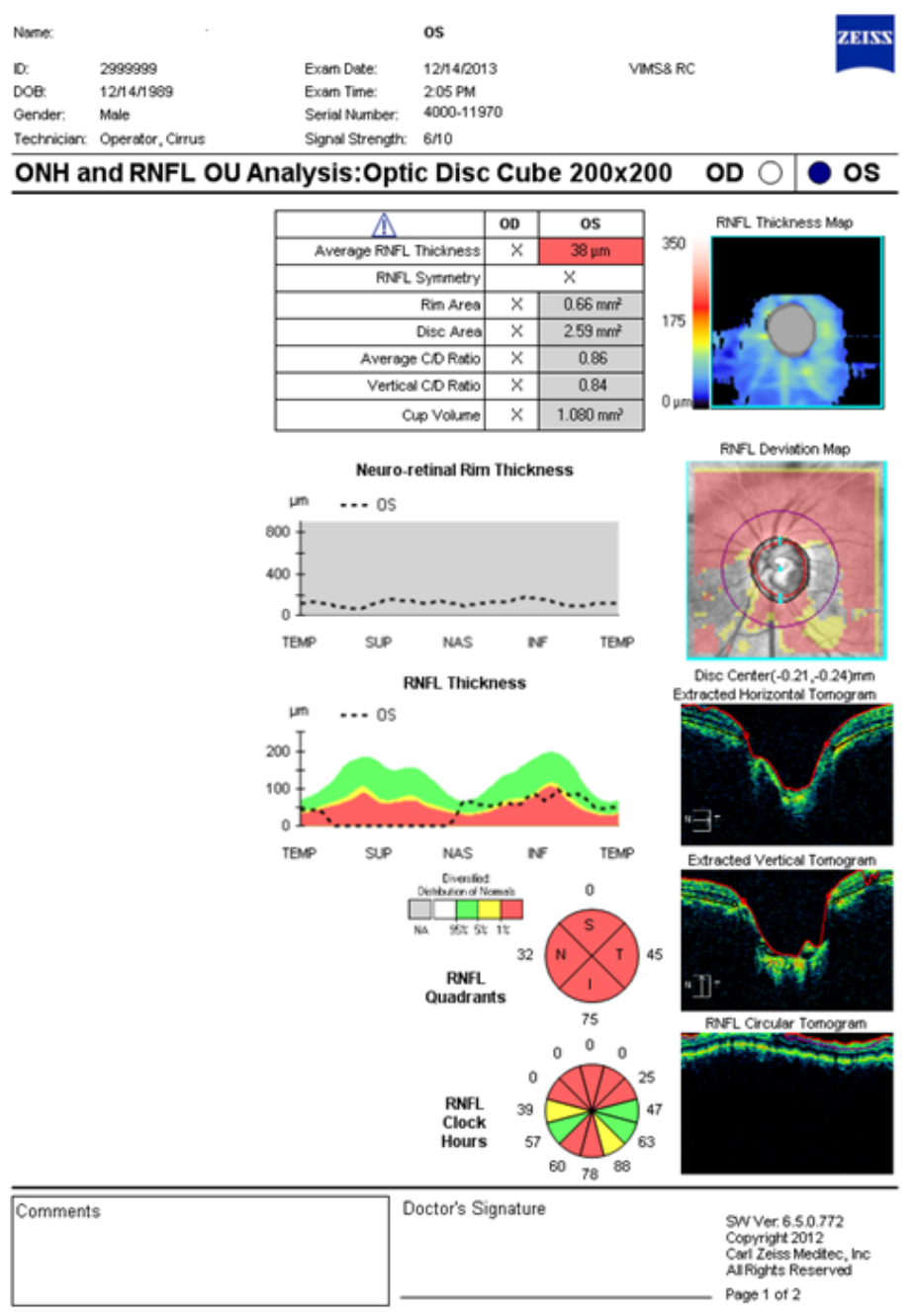


DISCUSSION: Anterior segment dysgenesis is a group of rare autosomal dominant condition including posterior embryotoxon, Axenfeld- Rieger syndrome, Peter's anomaly and aniridia. Several different gene mutations encoding for transcriptional regulators have been described. These specify migration and differentiation of mesenchymal progenital cells of neural crest origin into distinct anterior segment tissues. Interplay between PITX2 and FOXC1 explains phenotypic variability and genetic heterogeneity of anterior segment dysgenesis.1,3 Main features are bilateral developmental ocular abnormalities which may be asymertical. ${ }^{4}$

This disorder is seen is approximately $1 / 200,000$ live births. There is no sex predilection. Most cases are diagnosed during infancy or childhood; however, glaucoma typically occurs in late childhood or adulthood. 4,5

Defects in differentiation, migration, or arrested development of neural crest cells in the anterior chamber, facial bones, teeth, cardiovascular system, and periumbilical skin are considered to be the etiological basis for the systemic and ocular findings characteristic of ARS.

Axenfeld-Rieger syndrome is a bilateral, heterogeneous condition and may include developmental abnormalities in the anterior chamber angle, iris, and trabecular meshwork. Correctopia, polycoria, ectropion uveae, posterior embryotoxon, and increased intraocular pressure are common ophthalmologic findings with ARS. Photophobia may be a symptom resulting from the pupillary and iris abnormalities.

The iris strands adherent to the posterior embryotoxon can range from fine threadlike strands to broad bands of iris tissue. Likewise, the iris stroma may be grossly abnormal including generalized atrophy with correctopia, ectropion uveae, and often is similar in clinical appearance to iridocorneal endothelial syndrome (ICE). ${ }^{5}$

Glaucoma is seen in approximately $50 \%$ of the cases with ARS. Development arrest of the neural crest cells with their retention in the anterior chamber angle during gestation results in incomplete development of the trabecular meshwork or Schlemm canal. The extent of iris defects and iris stands in the angle do not correlate well with the severity of glaucoma. Although glaucoma may present in early infancy, most cases occur during adolescence or early adulthood.

CONCLUSION: The ocular and systemic features of anterior segment dysgenesis are well described in literature. These conditions may only be a part of manifestation of potentially blinding syndrome, representing the tip of iceberg. Hence, our case emphasizes the grave importance of a thorough ocular examination, detailed family history, examination of other members of the family, early diagnosis and long term follow up to avoid irreversible loss of vision.

\section{REFERENCES:}

1. Borges AS, Susanna R Jr, Carani JC, Betinjane AJ, Alward WL, Stone EM, Sheffield VC, Nishimura DY. Genetic analysis of PITX2 and FOXC1 in Rieger Syndrome patients from Brazil. J Glaucoma. 2002 Feb; 11(1):51-6.

2. Robert L. Stamper, Marc F.Leiberman, Michael V.Drake, Becker-Shaffer's Diagnosis and Therapy of the Glaucomas, 8th Edition. Elsevier Health Sciences; 2009.

3. R. Rand Allingham, Karim F. Danji, Sharon Freedman, Sayoko E. Moroi, Douglas J. Rhee. Shields' Textbook of Glaucoma, 6th Edition. Wolters kluwer (India); 2011. 


\section{CASE REPORT}

4. Jack J Kanski , Brad Bowling. Clinical Ophthalmology: A systemic Approach, 7th Edition. Elsevier Sanders; 2011.

5. Sowden JC, Molecular and developmental mechanism of anterior segment dysgenesis. Eye, 2007; 2 1:1 310 \& \# 8211; 1318, doi: 10.1038/ sj.eye.6702852. [PubMed] [Cross Ref].

\section{AUTHORS:}

1. Tasneem A. F.

2. Vittal Nayak I.

3. Shwetha B. A.

4. Ali Akbar Jafarian Lari

\section{PARTICULARS OF CONTRIBUTORS:}

1. Professor, Department of Ophthalmology, Vydehi Institute of Medical Sciences and Research Centre, Bangalore.

2. Professor and HOD, Department of Ophthalmology, Vydehi Institute of Medical Sciences and Research Centre, Bangalore.

3. Assistant Professor, Department of Ophthalmology, Vydehi Institute of Medical Sciences and Research Centre, Bangalore.
4. Post Graduate, Department of Ophthalmology, Vydehi Institute of Medical Sciences and Research Centre, Bangalore.

\section{NAME ADDRESS EMAIL ID OF THE} CORRESPONDING AUTHOR:

Dr. Shwetha B. A, \#5/6, 32 $2^{\text {nd }}$ Cross, Next to Water Tank, K. S. Layout, Bangalore - 76 .

E-mail: bashwetha@yahoo.co.in

Date of Submission: 11/03/2014. Date of Peer Review: 12/03/2014. Date of Acceptance: 18/03/2014. Date of Publishing: 26/05/2014. 